\title{
ACCIÓN, DISCURSO Y METÁFORA. SOBRE EL LENGUAJE EN H. ARENDT
}

\author{
ACTION, DISCOURSE, AND METAPHOR: ABOUT THE LANGUAGE IN
} H. ARENDT

\author{
Octavio Uña Juárez \\ Universidad Rey Juan Carlos, Madrid. España/Spain \\ octavio.una@urjc.es
}

Recibido/Received: 20/06/2014

Modificado/Modified: 29/08/2014

Aceptado/Accepted: 19/09/2014

\section{RESUMEN}

Toda la obra de Arendt se alimenta de múltiples registros y de ámbitos variados de conocimiento: filosofía y ciencias sociales especialmente, pero también de la literatura y la poesía. En el lenguaje se acumula el sentido. Pensar consistirá en un ejercicio de "descongelación" de los significados que habitan en el lenguaje. Por ello, no hay pensamiento sin palabra. El lenguaje es el medio donde se manifiesta el pensamiento. Es más, el pensamiento necesita el lenguaje no sólo para expresarse, sino para ponerse en movimiento. Por otra parte, tal es la prioridad del lenguaje, que las palabras y sus articulaciones son las únicas armas que tenemos para dar cuenta de los hechos del mundo. A su vez, el lenguaje funda la comunidad. La ciudad y la sociedad son por el carácter público del "logos". La ciudad, la "politeya", es construcción de hechos y palabras. Con la palabra y la acción nos insertamos en el mundo propiamente humano. La acción es realmente política por la palabra, por el discurso. La sociedad es cuando los hombres se hablan y se sienten. Y cuando se pierde "la poderosa luz del ágora" se desvanece la comunidad. Si las aportaciones de Arendt al lenguaje en su relación con el conocimiento y con la vida social son extraordinariamente creativas, no lo son menos en lo relativo al lenguaje poético en su función de originancia y creatividad. Bajo la influencia de Heidegger y en la larga sombra de Hölderlin, para Arendt en el lenguaje vive el origen: recordar será la esencia del pensar, como ya estableciera Platón.

\section{PALABRAS CLAVE}

Arendt, Heidegger, significación y conocimiento, lenguaje poético, metáfora, lenguaje y sociedad.

\section{SUMARIO}

1. Introducción. Nuevos "caminos" hermenéuticos sobre el lenguaje. 2. Indicación metodológica. 3. Poética y lenguaje. 4. El lenguaje y la "condición humana". 5. El lenguaje y la "vida del espíritu". 6. Breve nota conclusiva. Bibliografía.

\section{ABSTRACT}

The entire work of Arendt feeds from multiple records and various fields of knowledge: philosophy and social sciences especially, but also literature and poetry. Sense is accumulated in the language sense. Think consist of an exercise of "thawing" of meanings that inhabit the language. Therefore, there is no thought without words. Language is the medium in which manifests thought. Indeed, the thought needs language not only for speech, but to get moving. Moreover, such is the priority of language, that words and their joints are the only weapons we have to account for the facts of the world. Moreover, language 
founds community. The city and society are by the public nature of the "logos". The city, the "Politeya" is construction of facts and words. By word and action we fit into the strictly world. The action is really policy by the world, by the speech. The society is when men talk and feel each other. And when we lose "the powerful light of the agora" lost community. If Arendt's contribution to language in its relation to knowledge and social life are extraordinarily creative, are not least with regard to poetic language in its role of creativity. Under the influence of Heidegger and Hölderlin's long shadow, for Arendt in the source language lives: remembering is the essence of thinking, as Plato stated.

\section{KEYWORDS}

Arendt, Heidegger, significance and knowledge, poetic language, metaphor, language and society.

\section{CONTENTS}

1. Introduction. New hermeneutical "paths" about language. 2. Methodology. 3. Poetics and language.

4. Language and the "human condition". 5. Language and the "spiritual life". 6. Brief conclusions. References.

\section{INTRODUCCIÓN. NUEVOS “CAMINOS” HERMENÉUTICOS SOBRE EL LENGUAJE}

No vamos a detener aquí la reflexión en aquel dicho de Wittgenstein: "Las palabras son como la piel sobre un agua profunda" (Wittgenstein, 1982: 91) ni en aquella otra afirmación de Habermas: "El "logos" del lenguaje se sustrae a nuestro control, y sin embargo somos nosotros, los sujetos capaces de hablar y actuar, quienes se entienden entre sí en este medio" (Habermas, 2008: 36). Tampoco podemos extendernos aquí, como piden de suyo la amplitud y profundidad del asunto, en el aserto arendtiano: "Nadie actúa a menos que el actuar haga presente su latente yo" (Arendt, 1993, 201). Queda para otros trabajos y otros días la indagación en el temario altamente sugeridor del lenguaje en la obra de Arendt: que en el lenguaje vive el origen, que en el lenguaje va un almacenamiento de sentido, que el mismo pensar viene a ser un proceso de descongelación de palabras, que en los "tiempos de oscuridad" se oculta el carácter público del "logos", "la poderosa luz del ágora", que el habla forja y mantiene la comunidad, que, cuando perdemos la vinculación, se pierde también el poder revelador de la palabra, que en los convulsos acontecimientos de la historia, en especial en el sombrío y atormentado siglo $\mathrm{XX}$, se instala un vacío entre "el poder de las palabras" y los "sobresaltos del mundo" (Koselleck, (2012) estudioso del lenguaje en su relación a la realidad política y social, mostró como la historia de los conceptos nos ilustra en el tiempo histórico del presente). El discurso de Arendt, desde posiciones singulares y originales, se edifica desde muy diversas entradas histórico-teóricas. Fiel al lema de Heidegger: "Construid desde él la morada del hombre: el lenguaje" (Heidegger, 2010, 269). No se cumple en ella la sugerencia de Bacon sobre la construcción de la obra propia: "De nobis ipsis silemus". Su biografía es la base y el campo de labrantío de su peculiar visión del hombre, la sociedad y el poder. Ella mira al escenario del pasado siglo y comprueba el gran fracaso de la comprensión, la soledad de la teoría así como la total separación entre las palabras y los hechos (muy acertadamente se ha dicho que "la historia es lenguaje" y que "el pasado se nos presenta bajo la forma de signo" (Lledó, 2012: 180-181). Ella constata igualmente que una "cierta sordera a los significados lingüísticos ha tenido como consecuencia un tipo de ceguera ante las realidades a las que corresponden" (Arendt, 1974: 145-146). Palabras como "tiranía", "totalitarismo", "fascismo" han aparecido como vacías de 
significado para la sociedad. Para la pensadora judía el lenguaje dice de lo originario y creador y el recordar viene a ser la sustancia del pensar. En el lenguaje se acumula el sentido, es un "pensamiento congelado".

El lenguaje, como proteica morada del pensamiento, es el gran recurso para nombrar, definir y comprender los hechos, "lo que es", la realidad misma. Pero el lenguaje pierde su poder epifánico y novador, su fuerza de desvelamiento y anuncio, cuando se ocultan y desaparecen las relaciones sociales y los vínculos comunitarios. El lenguaje entonces, como quería Wittgenstein, "marcha en el vacío". Nuestra autora repite hasta la saciedad que la vida social es ineludiblemente por el "logos". El eclipse del "logos" coincide con los "tiempos de oscuridad": "Los hombres aislados carecen de poder" (Arendt, 1982: 611), "El poder surge allí donde las personas se juntan y actúan concertadamente" (Arendt, 1974: 154). Palabra y acción -acción que reviste la especificidad de política por la palabra- nos insertan en el mundo propiamente humano y construyen el "espacio público", como Kant formulara para la época moderna y Habermas glosara para la sociedad democrática. Somos porque hablamos y somos verdaderamente políticos, ciudadanos, por esa palabra de la significación proteica, inauguradora, "alba originaria", rebasadora de las situaciones dadas, adelantadora y creadora. La palabra, por el contrario, deviene estéril, insignificante, ausente, cuando se desvanece la relación, la interacción y la cohesión de aquel "animal político" que fuera el hombre. Ella ve la desgracia mayor de la sociedad de su tiempo en la pérdida del "espacio asociativo", que es el espacio deliberativo, constituido por la libertad y la igualdad, en la aminoración y pérdida de la "poderosa luz del ágora" (Roiz, 2003:165-200 y 201-242). Arendt sostiene taxativamente que "los hombres en plural, o sea, los que viven, se mueven y actúan en este mundo, únicamente experimentan el significado debido a que se hablan y se sienten unos a otros y a sí mismos". Entre otros brillantes textos.

Tiene en su haber la ilustre alumna de Husserl, Heidegger y Jaspers brillantes páginas sobre el lenguaje: el lenguaje y la sociedad, el lenguaje y el pensamiento, especialmente en sus escritos La vida del espíritu y La condición humana. De excelencia son igualmente sus reflexiones sobre el lenguaje y la poesía, sobre la metáfora y lo inefable. En Ensayos de comprensión se hace gran elogio de la lengua materna y se celebra la lengua alemana (Arendt, 2005: 29-30). En Los orígenes del totalitarismo discurren mil sugerencias sobre conocimiento y poder, sobre "adoctrinamiento ideológico" y "propaganda política". Nuestra autora parte de dos presupuestos en el célebre escrito: que en el siglo XX las ideas han sido "disueltas por los hechos" y que igualmente cunde el vacío entre el poder de las palabras y los sobresaltos del mundo. Ya Adorno dejó también lúcidas intuiciones sobre las relaciones y trastiendas varias entre lenguaje e ideología (Adorno, 1982; Barth, 1951; ...). Este conocido texto se propone una muy precisa finalidad y de algún modo repite el celebrado propósito -a la búsqueda y captura de los "ocultos schematismos et motus"- del autor de Novum Organum (Uña Juárez, 1989:38-42). Así se formula explícitamente: este libro "fue escrito con el convencimiento de que sería posible descubrir los mecanismos ocultos mediante los cuales todos los elementos tradicionales de nuestro mundo público y espiritual se disolvieron en un conglomerado donde todo proceso parece haber perdido su valor específico y tornándose irreconocible para la comprensión humana, inútil para los fines humanos" (Arendt, 1981: 12). 


\section{INDICACIÓN METODOLÓGICA}

Aunque no se enuncien explícitamente, al modo marxiano sobre Feuerbach, las tesis fundamentales de Arendt sobre el lenguaje, partimos de ellas y desde ellas formularemos esta introductoria y mínima reflexión. Damos por sentado una prevención implícita en el "corpus" arendtiano de variados aspectos temáticos básicos, especialmente los relativos al conocer y al pensar en sus relaciones con el lenguaje, la ideología, la significación, la metáfora. De igual modo, la subyacencia del fondo argumental agustiniano, heideggeriano y existencialjaspersiano en perspectivas y tomas de posición teóricas.

Acotamos aquí algunos subcampos de su producción, siquiera indicativamente, como el de su teoría de la poesía y su misma producción poética, ricos en aspectos sobre la palabra, la intersubjetividad, la dialogía y la comunicación, y algunas aportaciones más sugerentes de $L a$ vida del espíritu y La condición humana (las vinculaciones del lenguaje con el conocimiento, la memoria, la significación, la metáfora, la escritura, la acción humana, la sociedad y la vida política, etc.). Las "cosas mismas" de nuestra reflexión son los textos mismos de la filósofa, el texto objetivo, evitando el recurso de la comparación y la referencia y recurrencia de nuestra autora a Heidegger, también, como hemos señalado, a la fenomenología husserliana, a la hermenéutica gadameriana, a la Escuela de Frankfurt -especialmente a Benjamin y a Adorno-, a Mannheim y a Adorno en las visiones y revisiones de la ideología, etc. (Sartori y Morlino, 1994; Morlino, 2010 y Uña Juárez, 2008). Tal comparativa se extendería, en un estudio dilatado y perfilado, a otras corrientes contemporáneas y posteriores a Arendt (Ricoeur, Barthes, Steiner, Bourdieu ...).

\section{POÉTICA Y LENGUAJE}

No exponemos aquí las aportaciones de Arendt a la poesía y, más concretamente, al lenguaje poético. Sí decimos que de algún modo su cultura literaria y, especialmente, el conocimiento de la poesía, al igual que sus creaciones poéticas, marcan su discurso y sus posiciones sobre el lenguaje. A la preferencia de la filosofía y la politología en sus aportaciones a este campo del lenguaje hay que añadir sus producciones poéticas como básicas e inherentes al trato arendtiano del lenguaje, siempre singular, sugerente y novedoso.

En sus escritos poéticos, hijos de la precocidad, en una hora vital marcada por la "melancolía profunda y vaga", por el abatimiento (Müdigkeit), habita una "indefensa y traicionada juventud" (Young-Bruehl, 2006: 88). Es su diario poético la crónica del "dolorido sentir" por la fugacidad de la vida, por la huida y pérdida de los contenidos del deseo, por la reiterada vivencia del amor fugitivo; en la experiencia, según sus versos, de que "todo declina" (Young-Bruehl, 2006, 99), trasunto del agustiniano "vergit in nihilum". Para la excelente glosadora Young-Bruehl, "sus poemas constituían la zona más íntima de su vida ...". Fue en la poesía y por medio de la poesía como llegó al conocimiento de sí misma. En sus poemas de adolescencia se halla cuestionado si saldría triunfante de su temprana pérdida, su sentimiento de ser "unheimlich", rara o extraña (Young-Bruehl, 2006: 64). Young-Bruehl dice también ser Heidegger su gran maestro y su amante, "en la tradición de la poesía romántica alemana". Igualmente concluye que "la lengua alemana fue su hogar (Heimat)" (Young-Bruehl, 2006: 64). De la Europa prehitleriana, a la que dice no añorar, queda para la pensadora la lengua: "El alemán es, en todo caso, lo esencial que ha quedado y lo que yo siempre he conservado conscientemente" (Arendt, 2005:25). Como judía alemana había hecho de la "Bildung" su destino de libertad e igualdad: “... la vivencia de oír hablar alemán 
por las calles. Para mí un gozo indescriptible" (Arendt, 2005:32). Hannah a su vez dice que de su cultura judía queda y permanece la lengua: "No hay sustituto de la lengua materna" (Arendt, 2005:30), "Hay una diferencia abismal entre tu lengua materna y todas las demás" (Arendt, 2005:29). Entre otras destacadas figuras del pensamiento o de las letras se me ocurre traer a presencia aquí la de Czeslaw Milosz (1911-2004), nacido en Vilna y muerto en Cracovia, cuya familia pertenecía a la alta burguesía polaca, quien, hablando polaco se consideró siempre como un escritor polaco, que en el poema "Lengua mía fiel", del libro Ciudad sin nombre (1969), escribió: "Lengua mía fiel, / te he servido... / Has sido mi patria... / Pero sin ti, ¿quién soy yo?”. Parecidas reflexiones comparativas podrían hacerse a propósito del autor de Masa y poder, el escritor judío, de ascendencia española, el Nobel Canetti y de otros muchos pensadores y escritores judíos, que escribieron preferentemente en alemán o ruso (Del Olmo, 2006).

Hannah Arendt y Martin Heidegger. Martin Heidegger y Hannah Arendt. Ella, joven estudiante, él, célebre filósofo, gran profesor y seductor de los embelesados alumnos. En Marburg es el encuentro e idilio, de 1924 a 1926. Arendt, "extraña de tierra extraña" (ArendtHeidegger, 2000:75), de "carácter melancólico y vulnerable" (Ettinger, 1995:15), quien se lamenta de su juventud desvalida y traicionada" (Wollin, 2003:70).

Heidegger, quien afirmara ser Arendt para él la "pasión de su vida", la inspiradora de su trabajo, y su proximidad, "luz del sol" (Arendt-Heidegger, 2000:50). De los poemas de Heidegger dice Arendt: "La lengua alemana se ha enriquecido con algunos poemas muy hermosos" (Arendt-Heidegger, 2000:389-390). De este célebre epistolario comenta la editora Ursula Ludz: "El lector... se convierte así en beneficiario de un lenguaje 'elevado', poco expresivo, de un lado y con matices poéticos, de otro" (Arendt-Heidegger, 2000:389).

En tal correspondencia amorosa, filosófica y literaria (para posiciones nazis y antisemitas del filósofo: Heidegger, 2014), se habla por antonomasia de Goethe, Hölderlin, Man, George, Rilke, Keller, Mörike, Trakl, Mallarmé, San Agustín, Schelling, Kierkegard y de su admirada Rahel Varnhagen.

La "melancholische Denkerin der Moderne", como la calificara Seyla Benhabid, comenzó a leer poesía y a dar rienda suelta a sus afanes creativos a los diecisiete años (un año antes había leído la Crítica de la razón pura y La religión dentro de los límites de la estricta razón (De Zan, 2004:211-224)). Jovencísima devota de Goethe, desarrolló una prodigiosa memoria, también en el campo de la poesía, desde los doce años. Confiesa saber de memoria "una buena parte de la poesía alemana" (Arendt, 2005:29). A ello hay que añadir sus amplios estudios de filosofía y teología así como de la lengua griega ("Siempre he amado la poesía griega. Y la poesía ha tenido gran presencia en mi vida" (Arendt, 2005:29)). Aunque, como sostiene E. Young-Bruehl (2006:64), "el talento de Hannah Arendt no era un talento poético", su camino creativo y sus ejercicios poéticos la llevaron al autodescubrimiento de su personalidad. Una excelente biógrafa resume así el plural fondo creativo de Hannah: "Su obra se caracteriza no sólo por una feroz independencia intelectual, sino también por la presencia de una multitud de registros, unos procedentes del debate filosófico y de las ciencias sociales, y otros de la literatura, del retrato filosófico y de la poesía" (Birulés, 2007:17). Es este, el de la creación poética un ámbito -unido a su brillante discurso expositivo, el ensayo filosófico- de grandísima aportación al lenguaje en la variada obra arendtiana (Villa, 1996 y Grunenber, 2006). Sobre ello esperamos volver más detenida y perfiladamente. 


\section{EL LENGUAJE Y LA "CONDICIÓN HUMANA"}

Bajo la influencia de la filosofía de la existencia, especialmente de sus maestros Heidegger (Sein und Zeit) y Jaspers (Philosophie), nuestra pensadora sostiene como premisa clásica que la libertad cobra sentido en la actuación del hombre en el mundo: la libertad existencial es elección y posibilidad y se concreta en el jaspersiano "actuar en la praxis concreta". El heideggeriano "habitar" hace de la existencia un acontecimiento propiamente humano a través del trabajo, el pensamiento y la acción (Arendt, 2013:63-126). La acción supone el horizonte del otro y ello es dado por el habla. Arendt se sitúa también en la tradición de la filosofía de la acción (Aristóteles, S. Agustín, Fichte, Hegel, Marx. Fichte concluyó: "Hacer, hacer, para eso existimos" y Goethe sentenció: "Al principio fue la acción"). Arendt va a desarrollar una brillante exégesis de la acción y de la acción política, como características básicas de la humana condición, aunque su original discurso haya tenido sus contestaciones (Virno, 2003:90). Hija del "estar situado" es la acción política, dada y advenida en el entramado de otras acciones y concreciones de la libertad. La acción política es social. La libertad de ser y de actuar torna también poética, creadora, a esta acción originante e innovadora sobre las variadas determinaciones de la existencia humana. "La política, dice la pensadora, nace en el espacio que está entre los hombres. El "mundo" vendrá a ser el ámbito de la política. Ella se concreta y es desde lo público, ella radica en el actuar y hablar juntos los humanos. La vida pública, la vida política es la expresividad humana, el conjunto de los humanos significados y sentidos. Nuestra autora se sitúa en el centro de los discursos sobre el lenguaje.

Tributaria de la fenomenología heideggeriana: la palabra apofántica, la verdad como desvelamiento y como patencia de la realidad (supresión de los velos, adecuación de la realidad consigo misma, resurgimiento del reino del olvido...), entre otras aportaciones de Sein und Zeit y Platonslehre von der Wahrheit. También por las líneas de investigación enriquecidas por la teología: "oyente de la palabra" (Rahner), "la revelación como historia" (Pannenberg), además de las aportaciones del personalismo, de la filosofía dialógica, de Buber, Levinas, Ricoeur y Habermas(Uña Juáarez, 1984; Adrián Escudero, 2009; Grondin, 2003; Apel, 1991; Habermas, 2003 y 2011; Bengoa Ruiz de Azúa, 1992).

La acción sin el discurso carecería de su poder de revelación y sugerencia, de su poética e innovadora virtud y el ser humano aparecería sin su carácter de sujeto. "En la palabra hablada... se identifica como autor, anunciando lo que hace, lo que ha hecho y lo que intenta hacer" (Arendt, 1993: 202). Ello recuerda aquellas disquisiciones agustinianas sobre el tiempo del sujeto, que Arendt conoce muy bien desde la preparación del temario de su tesis doctoral: "praesens de praeteritis", "praesens de praesentis", "praesens de futuris". La acción pide, exige el discurso. "El discurso es útil en extremo como medio de comunicación e información" (Arendt, 1993:202).

En la acción y en el discurso los hombres aparecen propiamente como son, muestran su genuina identidad y se descubren como pertinentes al mundo humano (Arendt, 1993:203). Luhmann, en su reflexión sobre el lenguaje como elemento decisivo para activar la autopoiesis de la comunicación, sostiene que la aparición del lenguaje permite se generen acoplamientos "operativos", que puedan ser controlados reflexivamente por los participantes (Luhmann, 1997:211). La "cualidad reveladora", sostiene nuestra pensadora, se acrecienta y brilla "cuando las personas están con otras... en pura contigüidad" (Arendt, 1993:204). El agente se revela en su actuación, de lo contrario la acción pierde su especificidad y el discurso se trivializa. Heidegger categorizaba aquellas recaídas del lenguaje como "habladurías", la "nueva charla" que dice nuestra filósofa. Entonces la palabra nada muestra, 
nada anuncia, nada dice del sujeto de tal actuación. Las palabras así se tornan en un reino de la insugerencia, la inexpresividad e irrevelancia. "La acción sin un nombre, un "quién" unido a ella, carece de significado" (Arendt, 1995:205).

La acción es política solamente si va acompañada de la palabra. La acción política, en el devoto republicanismo arendtiano, deviene en la más caracterizada y elevada actividad humana (Esteban Enguita, 2006 y 2009). El amor al prójimo -como ella mostró en su original análisis de este concepto agustiniano- nos impele a asumir la ardua carga política. Para los humanos, para los ciudadanos, el nacimiento es la entrada en un mundo común, la aparición ante los otros, la constitución relacional de un mundo con otros (Mitsein). Tal mundo común es experimentado en el habla ("El mundo general es mi mundo", sostenía Husserl). La actividad política será tal si va acompañada de la palabra del discurso: "Sólo hablando comprendemos". El mundo, como querían Buber y la filosofía dialógica toda, es el "entre" nosotros, lo que nos vincula con otros, lo que nos acerca o nos distancia. Desde Aristóteles fue entendido el ser humano como ser de la acción, como ser de la relación y como ser político. Y actuamos en un mundo sociohistórico, como señaló A. Schütz, anterior a nosotros, coetáneo a nosotros y que nos sobrepasará en el tiempo. Actuamos con otros y el mundo se torna co-mundo (Mitwelt). La acción no se concreta aisladamente. Cada ser humano marca, signa el mundo con su personal acción. Acción que acontece en la libertad y la pluralidad. El pensamiento arendtiano sobre la acción debe insertarse y contrastarse con la tradición filosófica al respecto, como indicábamos. También con la tradición de la teoría sociológica: Weber, Pareto, Parsons, Luckmann y Elster, especialmente.

Aristóteles ve al ser humano como ser de la palabra y como ser político (Roiz Parra, 2002 y Campillo Meseguer, 2002). La política "se hace" con palabras. El lenguaje es para Aristóteles corolario y manifestación de la "politicidad" del ser humano (Coseriu, 1987:11). Coseriu establecía que el "lenguaje de la política" debería entenderse como léxico político, como modo de empleo de los signos lingüísticos en la política y como conjunto de procedimientos específicos de los discursos políticos (Coseriu, 1987:11). Sin entrar al comentario sobre la distinción entre lenguajes especiales y lengua común, diremos que el lenguaje político es "un uso especial de la lengua común" (Fernández Lagunilla, 1999:13). Nuestra pensadora consigue en estas creadoras páginas una brillante aportación al discurso político (Kerbrat-Orecchioni y Mouillard, 1984 y Tournier, 1997) al establecer que la esencia de la vida política coincide con aquella proteica y fundadora morada del hombre en el lenguaje, aquel hölderliniano "habitar poéticamente" y aquella heideggeriana "casa del ser".

\section{EL LENGUAJE Y LA "VIDA DEL ESPÍRITU"}

El profundo y original texto La vida del espíritu aporta una amplia reflexión sobre pensamiento y lenguaje, que merece un extenso y detallado estudio aparte. Presentamos aquí una breve secuencia de sus más sugerentes propuestas. Para nuestra autora, "el espíritu es el que requiere el lenguaje" (Arendt, 2002: 120). La recóndita actividad de la mente se manifiesta a través del lenguaje: los seres pensantes habitan en la necesidad de manifestarse y hablar. El "deus absconditus" del pensamiento -Hegel traducía el célebre verso virgiliano, "tantae molis erat romanam condere gentem", en este otro: "tantae molis erat seipsam cognoscere mentem"- tiene su teofanía en el lenguaje. Este viene a ser el gran vehículo y el patentizador de la ultimidad íntima y misterial de la mente humana. El "magnum 
profundum" que era el hombre para San Agustín se muestra, se torna de forma accesible y traducible. He aquí estas notas esenciales del lenguaje: la patencia, la apertura y la epifanía.

Este impulso de hablar viene constituido por la búsqueda de significado -decir es decir algo-, por la naturaleza significativa del lenguaje, también expresiva y comunicativa (Merleau-Ponty, 1964, Eco, 1976 y 1977 y Barthes, 1991 y 1996). El criterio del "logos" es la significación, no la verdad o falsedad. Las palabras no son por ello ni verdaderas ni falsas (Arendt, 2002:120). Así lo que la autora llama "necesidad de la razón" se realiza y cumplimenta con el pensamiento discursivo. Los pensamientos pueden ser tan solo como pensamientos dichos (Arendt, 2002:122). El lenguaje es comunicativo porque el ser humano, ser de razón, necesita y precisa comunicar su pensamiento. Se basa en la esclarecedora posición de Kant que establece que la razón "no se adapta al aislamiento, sino a la comunicación” (Arendt, 2002:121) (ya Góngora, en célebre composición, había establecido que el "diálogo" del sujeto consigo mismo se bastaba con "mis pensamientos").

Es inherente a la razón el viaje hacia el reino del significado y la ineludible búsqueda de éste. El animal lógico que es el humano está entregado a dar cuenta de la existencia, y a apoderarse del mundo, que pasa de realidad extraña a realidad cercana, propia y poseída. Ese tránsito de la "alteración" al "ensimismamiento", en expresión de Ortega, acontece en las palabras, en la nominación y bautismo del mundo (aquellas célebres posiciones de Arias Montano y Fray Luis de León sobre la palabra creadora, la relación entre los nombres y las realidades) (Arias Montano, 2006 y Perea Siller, 1998). No habrá pensamiento sin palabra, sin palabra oral o sin palabra en imagen. Pensar en palabras y pensar en imágenes. "La poesía... o incluso si se lee en voz alta, afectará al oyente de manera óptica; éste no se aferrará a la palabra que escucha sino al signo que recuerda, y a las visiones a que el símbolo se refiere" (Arendt, 2002:123). La razón especulativa se hace patente en las analogías, se manifiesta metafóricamente. La actividad mental "toma prestado su vocabulario de las palabras que en un principio pertenecían a la experiencia sensible..." (Arendt, 2002:124). El lenguaje filosófico y casi todo el lenguaje poético son metafóricos (el poético para algunos es "vivamente metafórico") Merleau-Ponty había escrito en 1945: "El lenguaje tiene un sentido. No presupone 'pensamiento'". La metáfora vincula al ámbito gnoseológico abstracto, el "pensamiento sin imágenes", la realidad de los conceptos (Bousono, 1966; Heuri, 1971; Le Gern, 1973; Ricoeur, 1976; Caminade, 1970; Tato, 1975 y Pozuelo Yvancos, 2003). El lenguaje, en el empleo de la metáfora en aquel especial ejercicio de la "usurpata translatio" de una realidad propia a otra impropia, como estableciera la estética agustiniana, nos permite pensar: "permite pensar, mantener intercambios con lo que no es sensible" (Arendt, 2002:123).

Abunda Arendt muy originalmente en las relaciones entre pensamiento y visión (teoría) y entre pensamiento y audición (narración), acentuando que el lenguaje es "el medio donde se manifiesta el pensamiento" (Arendt, 2002:141). El pensamiento muestra su insuficiencia, frente a los sentidos, para hacer patente lo inefable. Al igual que, como señala Heidegger desde Nietzsche, el lenguaje viene determinado por el ámbito de lo indecible. El pensamiento necesita el lenguaje para expresarse (expresión, significación, comunicación) y "lo necesita para ponerse en marcha" (Arendt, 2002:144).

De la mano de Benjamin, tan presente en su obra, las "iluminaciones" en las que Arendt quiere habitar teórica y metodológicamente suponen reivindicar el papel de la tradición, la transmisión del pasado, el análisis de los fenómenos, la investigación de la verdad y, de manera especial, la forma poética del pensamiento y el uso de las metáforas: aspectos varios de la hermenéutica y la metodología que concretó Benjamin en su filosofía crítica como "el pensamiento crudo". Central en el itinerario benjaminiano es el rico y central tema de la 
metáfora: su poder de transferencia y las posibilidades de remisión del orden conceptual al orden sensitivo-perceptivo. Dice de él Arendt en sus indagaciones sobre la metáfora, que "sin ser poeta pensaba poéticamente". Tal laborioso quehacer consigue que la transferencia lingüística confiera "forma material a lo invisible", siendo así "la metáfora como el don más importante del lenguaje" (Arendt, 1989:174).

Para Benjamin y Arendt no es el lenguaje formal y establecido el que nos entregará la realidad diversa y acumulada. El lenguaje, en su complejidad y riqueza, superará los límites que impiden describir el mundo. Por ello el grave oficio en torno a la verdad es "metaforizar" y "perforar en el lenguaje" (Arendt, 1989:209).

Queremos cerrar este breve y sugeridor inciso sobre las relaciones entre pensamiento y lenguaje, desde Heidegger y Arendt, con unas recientes palabras formuladas desde una profunda tradición: "La lengua piensa y nos piensa y nosotros podemos hacerlo en cuanto hablantes de ella, podemos pensar solo y exclusivamente desde ella, desde la lengua, con o contra ella, pero siempre a su través, siempre desde la fiel correspondencia que deriva de la "forma interna" de la lengua" (Martín, 2014:5).

Sobre la brillante aportación de Arendt al análisis filosófico y sociológico del lenguaje podrían haber sido dichas estas palabras de un fino expositor en torno al conocimiento y el lenguaje: "La importancia central que se atribuye también en los países de habla alemana al lenguaje se sigue debiendo hoy todavía a la necesidad de dar con un auténtico criterio de verificación de nuestras afirmaciones de comunicación intersubjetiva. Aquí radica una de las mayores dificultades tanto de la fenomenología como de la filosofía existencial propiamente dicha. Frente a estas dos direcciones del pensamiento contemporáneo, las filosofías basadas en la consideración del lenguaje parece que están en principio en mejores condiciones de abordar este problema, puesto que el lenguaje es el elemento propio de la intersubjetividad" (Inciarte, 2011:221).

Volveremos más detenidamente al lugar de la creatividad, de la sugerencia y la frescura que es la obra arendtiana.

\section{BREVE NOTA CONCLUSIVA}

En el lenguaje vive el origen. Esta básica y fundante característica del lenguaje hace de él la cálida morada, la última mansión. En el "habitar poéticamente" acontece el pensar como ya Heidegger mostrara en la celebrada conferencia de Darmstadt sobre el morar, el edificar y el pensar. El filósofo insiste sobre la naturaleza propia del lenguaje: lo originario y originante (Ursprung) del lenguaje, al cobijo del "alba originaria", metáfora celebrada. En el lenguaje son el significado y el sentido. Pensar, como hemos señalado, vendrá a ser una descongelación de los significados que se albergan en el lenguaje como en su íntimo habitáculo. Heidegger, especialmente el "joven Heidegger", desde posiciones un tanto crípticas y esotéricas, construyó y dotó, entre otros muchos, los conceptos de "Mitdasein", "Mitsein", "Miteinandersein", "Mitwelt"..., referidos a la relacionalidad humana, y los de "Rede", "Sprache", "Hören", "Schweigen"..., relativos al habla y al discurso, siendo original y rica su aportación a aspectos variados del lenguaje y la sociabilidad humana (Schiffer, 1962; Escudero, 2009; De Visscher, 1966 y Greisch, 1973). Líneas estas de pensamiento que la filósofa glosa, amplía y dota de propia mano al abundar en el lenguaje desde la sociología y la ciencia política. El hombre como ser político y como ser del "logos" adquiere una elevada, rigurosa y apasionada trama a lo largo de la obra arendtiana. 
Nuestra autora insiste igualmente en aquella tesis que establece que la razón es comunicativa y que ella no se ajusta ni se adapta al aislamiento. El pensamiento es si es dicho. En la creación de palabras el mundo pierde su extrañamiento. Sin palabra no es el pensamiento. El último latir de la razón es dar cuenta de la realidad, la irrefrenable búsqueda de significado y sentido. Mas la palabra es el arma apropiada de esta decisiva y fundadora batalla. El espíritu reclama el lenguaje; el pensamiento es manifestándose, es expresión. La razón se quiere en la comunicación, no en la enajenación y la soledad. Nombres y significados: "nomina, numina", "nomen est omen". Entre las que nuestra pensadora califica como "necesidades de la razón" va la del pensamiento discursivo. La razón pide de suyo comunicación, mostración y discurso.

En el largo debate histórico sobre la relación entre pensamiento y lenguaje y lenguaje y pensamiento, abierto por Platón, Aristóteles y la tradición estoica, que tiene en Aristóteles y Marx los máximos exponentes de las posiciones opuestas, Arendt aporta, ahondando en la "vida del espíritu", a las relaciones lenguaje y pensamiento nuevas y atinadas sugerencias, marcada esta su reflexión por el pensamiento de Heidegger, quien enfatiza en la proteica y constitutiva realidad del lenguaje.

De igual manera nuestra pensadora toma "aquel sendero que remite a lo mismo:/ la poesía y el pensar", sendero que transformó Heidegger en amplia avenida desde la reflexión pura y el análisis aplicado a creaciones de poetas, especialmente de Hölderlin. "El lenguaje, al servirse del uso metafórico, permite pensar, mantener intercambios con lo que nos es sensible" (Arendt, 2002:132). La metáfora dota de imágenes al pensamiento.

Estas indagaciones de nuestra autora sobre la naturaleza de la poesía misma y sobre la metáfora ocupan un lugar de originalidad y excelencia junto a las de Heidegger y Gadamer. De igual modo la reflexión arendtiana sobre la acción humana consigue también un destacado lugar en la tradición filosófica y sociológica de este temario, desde Aristóteles a Fichte y desde San Agustín a Hegel, Marx, Weber y Parsons. "Acción y discurso están estrechamente vinculados" (Arendt, 1993:202). El productor de cosas y palabras que es el hombre. Con palabras y actos se inserta el hombre en lo propiamente humano, como si de un "segundo nacimiento" (Arendt, 1993:201) se tratara.

\section{BIBLIOGRAFÍA}

ADORNO, Th. W. (1982). La ideología como lenguaje. Madrid: Taurus.

ADRIAN ESCUDERO, J. (2009). El lenguaje de Heidegger. Barcelona: Herder.

APEL, K. O. (1991). Teoría de la verdad y ética del discurso. Barcelona: Paidós.

ARENDT, H. (1974). La crisis de la República. Madrid: Taurus.

- (1981). Los orígenes del totalitarismo, 3. Totalitarismo. Madrid: Alianza.

- (1989). Hombres en tiempos de oscuridad. Barcelona: Gedisa.

- (1993). La condición humana. Barcelona: Paidós.

- (2002). La vida del espíritu. Barcelona: Paidós.

- (2005). Ensayos de comprensión 1930-1954. Escritos no reunidos e inéditos de Hannah Arendt.

Madrid: Caparrós.

- (2013). Existencialismo y compromiso. Barcelona: RBA.

ARENDT, H. y HEIDEGGER, M. (2000). Correspondencia 1925-1975. Barcelona: Herder.

ARIAS MONTANO, B. (2006). Libro de José o sobre el lenguaje arcano. Huelva: Universidad de Huelva.

BARTH, H. (1951). Ideología y verdad. México: FCE.

BARTHES, R. (1991). El imperio de los signos. Madrid: Mondadori. 
- (1996). La aventura semiológica. Barcelona: Paidós.

- (2002). El susurro del lenguaje. Más allá de la palabra y la escritura. Barcelona: Paidós.

BENGOA RUIZ DE AZÚA, J. (1992). De Heidegger a Habermas. Hermenéutica y fundamentación última en la filosofía contemporánea. Barcelona: Paidós.

BENHABIB, S. (2010). Politics in Dark Times. Encounters with Hannah Arendt. New York: Cambridge University Press.

BERSTEIN, J. (1996). Hannah Arendt and the Jewish Question. Cambridge: MIT Press.

- et al. (2001). Hannah Arendt. El legado de una mirada. Madrid: Sequitur.

BIRULÉS, F. (1995). La especificidad de lo político: Hannah Arendt. Valencia: Episteme.

- (2007). Una herencia sin testamento. Barcelona: Herder.

BLOCH, E. (1982). Sujeto-objeto: El pensamiento de Hegel. Madrid: FCE.

BOUSOÑO, C. (1966). Teoría de la expresión poética. Gredos: Madrid.

BOURDIEU, P. (1985). ¿Qué significa hablar? Madrid: Akal.

- (1988). Cosas dichas. Barcelona: Gedisa.

BUYSSENS, E. (1943). Les lenguages et le discours. Bruselas: Office de Publicité.

CAMINADE, P. (1970). Image et métaphore. Nancy: Bordas.

CAMPILLO, N. (2013). "Bibliografia". En Hannah Arendt: lo filosófico y lo político. Valencia: PUV. pp. 267-294.

CAMPILLO MESEGUER, A. (2002). "Espacios de aparición: el concepto de lo político en Hannah Arendt", en Daimon: Revista de filosofía, 26: 159-188.

COLLETTI, L. (1974). Ideología y sociedad. Barcelona: Fontanella.

COSERIU, E. (1987). "Lenguaje y política". En M. Alvar (coord.) El lenguaje político. Madrid: Friedrich Ebert - Instituto de Cooperación Iberoamericana, pp. 10-31.

CRUZ, M. (2006). El siglo de Hannah Arendt. Barcelona: Paidós.

DE VISSCHER, L.F. (1966). "La pensé du langage chez Heidegger", en Revue Internationale de Philosophie de Louvain, 64: 224-262.

DE ZAN, J. (2004). “Arendt y Kant”, en Daimon: Revista de filosofía, 33: 211-224.

DEL OLMO, G. (2006) Lo divino en el lenguaje: el pensamiento de Diótima en el siglo XXI. Madrid: Horas y Horas.

DIJK, T.A. van (1976). Pragmatics of Language and Literature. Amsterdam: Nort Holland.

ECO, U. (1976). Signo. Barcelona: Labor.

- (1977). Tratado de semiótica general. Barcelona: Lumen.

ESCUDERO, J. A. (2009). El lenguaje de Heidegger. Barcelona: Herder.

ESTEBAN ENGUITA, J. E. (2006). "Praxis, poder, libertad. Hannah Arendt y la determinación de lo político", en Revista de Occidente, 303: 69-77.

- (2009). Voluntad y responsabilidad en Hannah Arendt. Madrid: Biblioteca Nueva.

ETTINGER, E. (1995). Hannah Arendt-Martin Heidegger. New Haven: Yale University Press.

FERNÁNDEZ LAGUNILLA, M. (1999). La lengua en la comunicación política, 1. El discurso del poder. Madrid: Arco Libros.

FORTI, S. (1996). "Bibliografía de las obras de Hannah Arendt". En Vida del espíritu y tiempo de la polis. Hannah Arendt entre filosofía y política. Madrid: Cátedra, pp. 433-451.

- (1996). "Bibliografía de los estudios sobre Hannah Arendt". En Vida del espíritu y tiempo de la polis. Hannah Arendt entre filosofía y política, Madrid: Cátedra, pp. 453-495.

GREISCH, J. (1973). "Les mots et les roses. La métaphore chez Martin Heidegger", en Revue des sciences philosophiques et théologiques, 57: 433-455.

GRONDIN, J. (2003). Introducción a Gadamer. Barcelona: Herder.

GRUNENBER, A. (2006). Hannah Arendt und Martin Heidegger. Munich: Piper.

HABERMAS, J. (2003). La ética del discurso y la cuestión de la verdad. Barcelona: Paidós.

- (2008). ¡Ay Europa! Pequeños escritos políticos. Madrid: Trotta.

- (2011). Escritos filosóficos, 1, Fundamentos de la sociología según las teorías del lenguaje.

Barcelona: Paidós.

HEIDEGGER, M. (1987). De camino al habla. Barcelona: Serbal.

- (1989). Hölderlin y la esencia de la poesía. Barcelona: Anthropos. 
- (1995). Caminos del bosque. Madrid: Alianza.

- (2010). Pensamientos poéticos. Barcelona: Herder.

- (2014). Überlegungen II-VI (Schwarze Hefte 1931-1938). Frankfurt a. M.: Vittorio Klostermann.

HEURI, A. (1971). Métonymie et métaphore. Paris: Klincksieck.

HUMBOLDT, W. von (1991). Escritos sobre el lenguaje. Barcelona: Península.

INCIARTE, F. (2011). Tiempo, sustancia, lenguaje. Ensayos de metafísica. Barcelona: Planeta.

KERBRAT-ORECCHIONI, C. y MOUILLARD, M. (coords.) (1984). Le discours politique. Lyon: Presses Universitaires de Lyon.

KOLAKOWSKI, L. (1970). El racionalismo como ideología. Barcelona: Ariel.

KOSELLECK, R. (2012). Historias de conceptos. Estudios sobre semántica y pragmática del lenguaje político y social. Madrid: Tecnos.

KRISTEVA, J. (2000). El genio femenino: la vida, la locura, las palabras, 1. Hannah Arendt. Buenos Aires: Paidós.

LE GERN, M. (1973). Semántique de la métaphore et de la métonymie. Paris: Larousse.

LLEDÓ, E. (2012). La filosofía hoy. Filosofía, lenguaje e historia. Barcelona: RBA.

LUHMANN, N. (1997). Organización y decisión. Autopoiesis y entendimiento comunicativo. Barcelona: Anthropos.

MARTíN, J. (2014). "Pensar desde la lengua. A propósito del paradigma de la 'tradición velada", en Revista de Occidente, 394: 5-19.

MERLEAU-PONTY, M. (1964). Signos. Barcelona: Seix Barral.

MILLER, G. (1979). Lenguaje y comunicación. Buenos Aires: Amorrortu.

MORLINO, L. (2010). Introducción a la investigación comparada. Madrid: Alianza.

MOUNIN, G. (1969). Linguistique et Philosophie. Paris: De Minuit.

PACHET, P. (2008). "Politique et humanité chez Hannah Arendt. L'autorité des poétes dans un monde sans autorité", en Cause Commune, 3: 114-121.

PEREA SILLER, F.J. (1998). Fray Luis de León y la lengua perfecta. Lingüística, cábala y hermetismo en "De los nombres de Cristo". Córdoba: Camino.

POZUELO YVANCOS, J. M. (2003). Teoría del lenguaje literario. Madrid: Cátedra.

PRINZ, A. (2001). La filosofía como profesión o el amor al mundo: la vida de H. Arendt. Barcelona: Herder.

RICOEUR, P. (1976). La métaphore vive. Paris: Seuil.

ROIZ, J. (2002). "Hannah Arendt como teórica de la política", en Daimon: Revista de filosofía, 26: 141-156.

- (2003). La recuperación del buen juicio. Teoría política en el siglo veinte. Madrid: Fuero Interno.

SARTORI, G. y MORLINO, L. (eds.) (1994). La comparación en las ciencias sociales. Madrid: Alianza.

SCHAFF, A. (1967). Lenguaje y conocimiento. México: Grijalbo.

SCHIFER, E. (1962). Die Sprache Heideggers. Pfullingen: Neske.

STEINER, G. (1990). Lenguaje y silencio: Ensayos sobre la literatura, el lenguaje y lo humano. Barcelona: Gedisa.

TATO, J. L. (1975). Semántica de la metáfora. Alicante: Instituto de Estudios Alicantinos.

TOURNIER, M. (1997). Des mots en politique. Propos d'etymologie sociale. Paris: Klincksieck.

UÑA JUÁREZ, O. (1979). Sociedad y ejercicios de razón. San Lorenzo de El Escorial: Escurialenses.

- (1984). Comunicación y libertad. La comunicación en el pensamiento de Karl Jaspers. San Lorenzo de El Escorial: Escurialenses.

- (1989). Materiales para una sociología del conocimiento. San Lorenzo de El Escorial: Edic. del Anuario Jurídico y Económico Escurialense.

- (2006). Estaciones de abril. Madrid: Dykinson.

- (2007). "De conceptos, lenguajes y metáforas. Carlos Moya y Octavio Paz", en AA. VV. Lo que hacen los sociólogos. Homenaje a Carlos Moya. Madrid: CIS, pp. 865-885.

- (2008). “Comunicación y lenguaje poético. El caso de Gadamer”, en RES, 9: 87-106.

- (2009). Nuevos ensayos de sociología y comunicación. Madrid: Universitas. 
- (2014). "Poética y comunicación. Aportaciones a la teoría de la comunicación y a la teoría de los objetos desde las Odas de Neruda", en Revista Internacional de Sociología, 3: 517-539.

VILLA, D. (1996). Arendt and Heidegger. The fate of the Political. Princeton: Princeton University Press.

VIRNO, P. (2003). Virtuosismo y revolución: la acción política en la era del desencanto. Madrid: Traficantes de sueños.

WITTGENSTEIN, L. (1982). Diario filosófico (1914-1916). Barcelona: Ariel.

WOLLIN, R. (2003). Los hijos de Heidegger. Madrid: Cátedra.

YOUNG-BRUEHL, E. (2006). Hannah Arendt. Una biografía. Barcelona: Paidós.

\section{Breve currículo:}

\section{Octavio Uña Juárez}

Doctor y premio extraordinario de doctorado por la Universidad Complutense de Madrid, catedrático de filosofía (IES), catedrático de sociología (Universidades de Santiago de Compostela, Complutense, Castilla-La Mancha y Rey Juan Carlos). Profesor en la Escuela Diplomática, en el CESEDEN y en un amplio número de universidades extranjeras. Ha sido decano y director del Real Colegio Universitario María Cristina (U. Complutense) y decano de la Facultad de Humanidades (U. de Castilla-La Mancha). Presidente del Instituto Ciencia y Sociedad y de la Asociación Castellano-Manchega de Sociología. Autor de una extensa obra de sociología y literaria. Director de un amplio número de investigaciones y tesis doctorales. De la Red de Estudios Interdisciplinarios sobre Ciencia y Tecnología (REICyT), con sede en la UNAM, investigador de Cátedra China. Sus líneas de investigación comprenden la sociología del conocimiento y la comunicación, la sociología de la cultura y la teoría sociológica. 